\title{
Insulin pump therapy in transient neonatal diabetes mellitus
}

\author{
Joong Heum Park, MD', \\ Jeong Hee Kang, MD', \\ Kyu-Hyung Lee, MD', \\ Nam-Hyo Kim, MD', \\ Han-Wook Yoo, MD, PhD ${ }^{3}$, \\ Dae-Yeol Lee, MD, $\mathrm{PhD}^{4}$, \\ Eun-Gyong Yoo, $\mathrm{MD}, \mathrm{PhD}^{1}$ \\ 'Department of Pediatrics, \\ CHA University College of Medicine, \\ Seongnam, ${ }^{2}$ Sungae Hospital, \\ Seoul, ${ }^{3}$ Department of Pediatrics, \\ University of Ulsan College of \\ Medicine, Seoul, ${ }^{4}$ Department \\ of Pediatrics, Chonbuk National \\ University Medical School, Jeonju, \\ Korea
}

Received: 5 August, 2013 Revised: 16 September, 2013 Accepted: 24 September, 2013

Address for correspondence:

Eun Gyong Yoo, MD, PhD

Department of Pediatrics, CHA Bundang Medical Center, CHA University College of Medicine, 59 Yatap-ro, Bundang-gu, Seongnam 463-712, Korea

Tel: $+82-31-780-5230$

Fax: +82-31-780-5239

E-mail:pedyoo@cha.ac.kr

\begin{abstract}
Neonatal diabetes mellitus (NDM) is a rare disease requiring insulin treatment. Its treatment is primarily focused on maintaining adequate glycemic control and avoiding hypoglycemia. Although insulin pump therapy is frequently administered to adults and children, there is no consensus on the use of insulin pumps in NDM. A 10 day-old female infant was referred to us with intrauterine growth retardation and poor weight gain. Hyperglycemia was noted, and continuous intravenous insulin infusion was initiated. However, the patient's serum glucose levels fluctuated widely, and maintaining the intravenous route became difficult within the following weeks. Continuous subcutaneous insulin infusion with an insulin pump was introduced on the twenty-fifth day of life, and good glycemic control was achieved without any notable adverse effects including hypoglycemia. We suggest that the insulin pump is a safe and effective mode for treating NDM and its early adoption may shorten the length of hospital stays in patients with NDM.
\end{abstract}

Keywords: Diabetes mellitus, Newborn infant, Insulin infusion systems

\section{Introduction}

Neonatal diabetes mellitus (NDM) is a rare (1:400,000 newborns) disease defined as hyperglycemia occurring within the first month of life that requires exogenous insulin and persists more than 2 weeks ${ }^{1)}$. There are two forms of NDM, transient NDM (TNDM) and permanent NDM (PNDM). TNDM, accounting for about $50-60 \%$ of NDM, recovers by 18 months of age $e^{2)}$.

Insulin therapy is crucial in NDM to obtain satisfactory weight gain and catch-up growth, especially because many of these newborns exhibit intrauterine growth retardation (IUGR) ${ }^{2}$. Avoiding hypoglycemia is another important goal because recurrent hypoglycemia at this age may result in neurodevelopmental sequela $\mathrm{e}^{3)}$.

However, data on the treatment of NDM, especially on the mode of insulin delivery, are very limited. Continuous intravenous insulin infusion is the preferred initial treatment, but long-term installation of an intravenous line is often intolerable in newborns with IUGR. Intermittent subcutaneous insulin injection is often tried, but hypoglycemia is frequent and sometimes inevitable ${ }^{2}$.

There are several reports on insulin pump therapy for NDM, but there is no consensus on the use of insulin pump therapy for $\mathrm{NDM}^{4,5}$. We present our recent experience with insulin pump therapy in TNDM, in which stable glycemic control was achieved without any complications.

\section{Case report}

A female infant was born at 38 weeks of gestation weighing 2,060 $\mathrm{g}(<3 \mathrm{rd}$ percentile) without any gestational complications. She was referred to our neonatal intensive care unit on 
the 10th day of life because of poor weight gain.

On admission, she weighed $1,920 \mathrm{~g}$ with a length of $43 \mathrm{~cm}$ $(<3$ rd percentile), and a head circumference of $33 \mathrm{~cm}$ (25th percentile). There was no abnormal finding on physical and neurologic examinations. There was no evidence of hepatic/ renal dysfunction or exocrine pancreas insufficiency

Her initial serum glucose level was $160 \mathrm{mg} / \mathrm{dL}$. The next morning, her blood glucose measured $557 \mathrm{mg} / \mathrm{dL}$ and urine contained $4+$ glucose without ketone. Her serum C-peptide concentration was $0.45 \mathrm{ng} / \mathrm{mL}$ and insulin was $1.53 \mu \mathrm{U} / \mathrm{mL}$. Antibodies for glutamic acid decarboxylase and islet cells were both negative.

Continuous intravenous insulin infusion was started, with regular insulin diluted in a 1:100 mixture with normal saline, and the patient started to gain weight. Target blood glucose was 100 to $360 \mathrm{mg} / \mathrm{dL}$. Blood glucose was monitored every 3 hours. When hypoglycemia was noted, $2 \mathrm{~mL} / \mathrm{kg}$ of $10 \%$ glucose solution was given intravenously, and blood glucose was checked after 30 minutes. The rate of insulin infusion was titrated according to blood glucose, and it was maintained between 0.016 and $0.03 \mathrm{U} / \mathrm{kg} / \mathrm{hr}$. However, the glucose levels fluctuated widely, and maintaining an intravenous route became difficult within the following weeks.

On the 25th day of life, continuous subcutaneous insulin infusion (CSII) with an insulin pump was commenced. Insulin lispro (Humalog, Lilly, Indianapolis, IN, USA) was administered in a 1:10 dilution at an initial basal rate of 0.016 $\mathrm{U} / \mathrm{kg} / \mathrm{hr}$, according to the most recent dose of intravenous infusion. Hyperglycemia was still frequent during the first week of CSII, but hypoglycemic episodes disappeared after the adoption of insulin pump therapy. The basal rate of CSII was maintained between 0.021 to $0.023 \mathrm{U} / \mathrm{kg} / \mathrm{hr}$ without meal bolus. Stable glycemic control was achieved within one week as the insulin pump settings were optimized (Fig. 1). The patient was transferred to a general ward, and her parents were educated about insulin pump therapy. The patient was discharged on the 38th day of life, weighing 3,180 g. Molecular analysis revealed paternal disomy of chromosome 6, suggesting TNDM (Fig. 2). She did not have activating mutations of $K C N J 11$ gene.

The insulin was gradually reduced over the following months. At 4 months of age, she weighed $6.7 \mathrm{~kg}$; her glycosylated hemoglobin was 5.3\% and C-peptide level was $1.09 \mathrm{ng} / \mathrm{mL}$. There were no significant cutaneous or systemic complications associated with insulin pump therapy. Insulin was discontinued

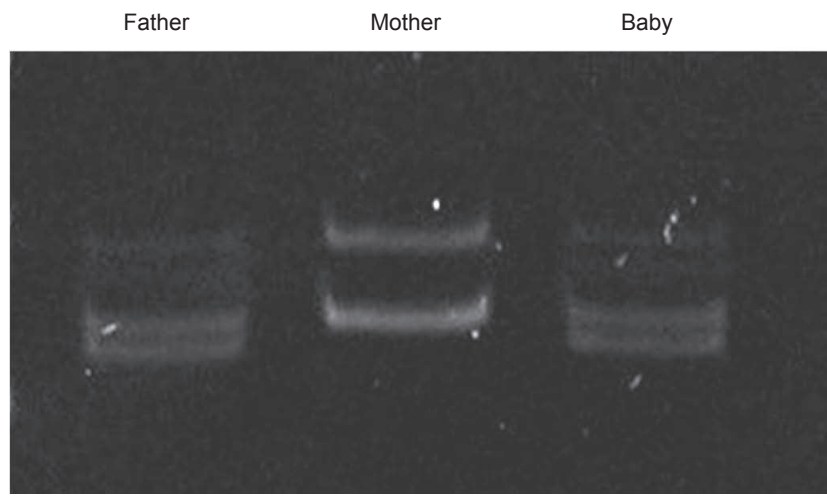

Fig. 2. DNA polymorphism analysis of chromosome 6 for D6S286 shows paternal disomy, suggesting transient neonatal diabetes mellitus.

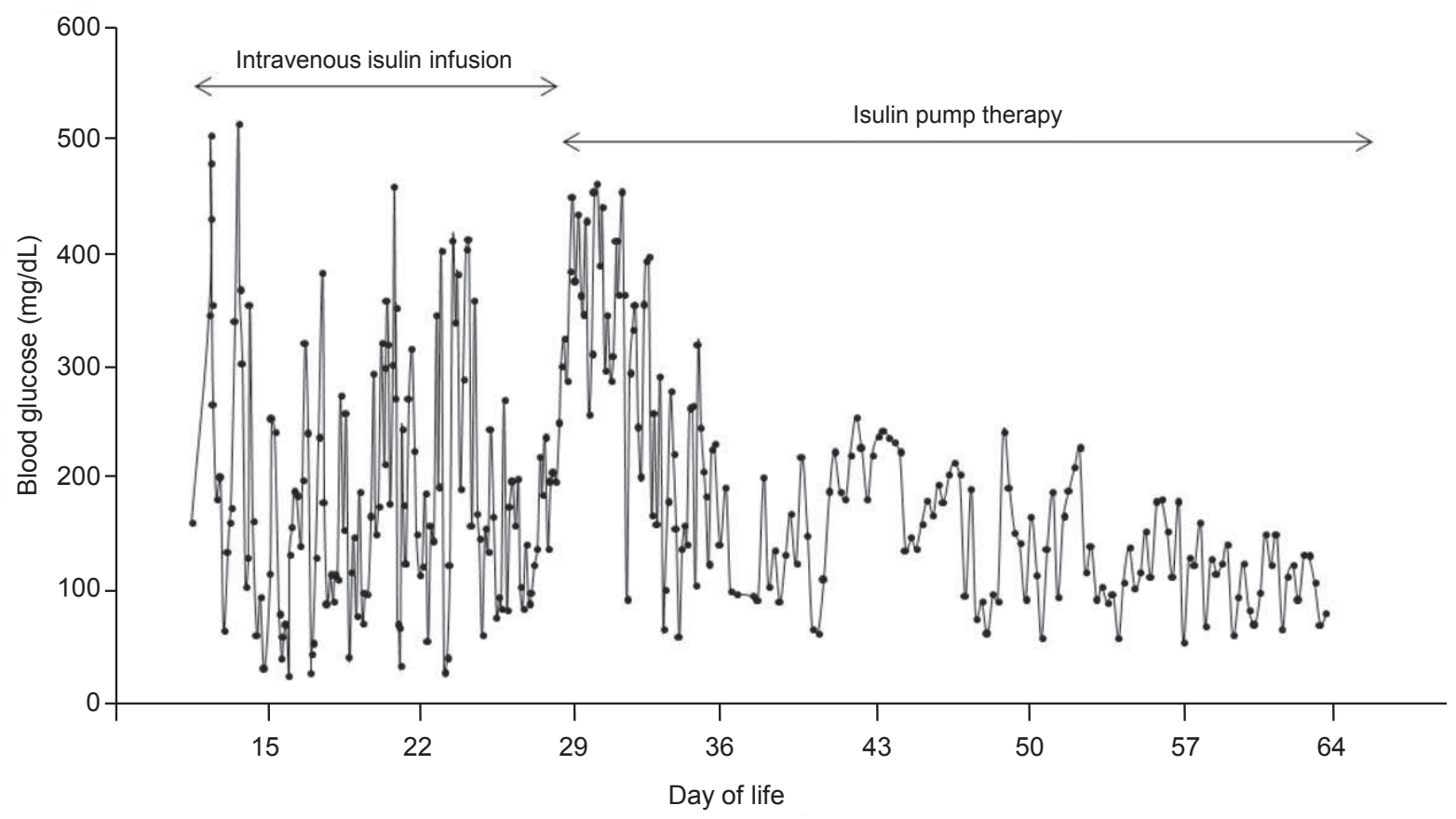

Fig. 1. Serial changes of patient's blood glucose levels of the show that insulin pump therapy offers better glycemic control than intravenous insulin infusion does. 
at 5 months of age. At 7 months of age, she weighed $8.0 \mathrm{~kg}$ (2550 th percentile) with a height of $68 \mathrm{~cm}$ (50th percentile).

\section{Discussion}

The clinical features of TNDM include severe IUGR, hyperglycemia that begins in the neonatal period and resolves by age 18 months, dehydration, and absence of ketoacidosis. Because the plasma concentration of insulin is low at the time of diagnosis, it is assumed that low birth weight is a result of low in utero levels of insulin, an important prenatal growth factor $^{6}$. Although the prognoses may differ, TNDM cannot be distinguished from PNDM based on clinical features because considerable overlap exists between them ${ }^{2)}$.

Genetic testing provides a useful tool for identifying TNDM from PNDM. Genetic mutations such as activating mutations in the KCNJ11 gene encoding Kir6.2 subunit or in the ABCC8 encoding SUR1 subunit of the pancreatic KATP channel, were reported to be associated with $\mathrm{PNDM}^{7-9)}$. These mutations result in overactive channels, leading to hyperpolarization of $\beta$ cells and reduced insulin secretion. On the other hand, abnormalities in chromosome 6 including paternal uniparental disomy and duplication of $6 q 24$ on the paternal allele have been demonstrated in patients with TNDM ${ }^{2,10,11)}$. Overexpression of imprinted genes at 6q24 (PLAGL1 and HYMAI) has been reported to result in $\mathrm{TNDM}^{6)}$. Our patient had paternal disomy of chromosome 6 , which predicts TNDM, and went into remission at 5 months of age.

Treatment of NDM has been primarily focused on maintenance of stable glucose levels and avoidance of hypoglycemia. Intravenous insulin infusion remains the first-line strategy in NDM to achieve satisfactory glycemic control in a titratable manner ${ }^{4)}$. However, long-term intravenous access in newborns with IUGR is very complicated, and requires prolonged hospitalization.

Intermittent subcutaneous insulin injection is also a conventional approach for treatment of NDM. Subcutaneous injection of intermediate-acting insulin twice a day is no longer recommended in NDM because it frequently induces hypoglycemia ${ }^{2)}$. Long-acting basal insulin potentially provides background insulin requirements, but has not yet been approved for neonates in most countries ${ }^{2}$. The management of hypoglycemic episodes may be complicated by these agents because their effects persist for more than 20 hours after injection. Furthermore, absorption of subcutaneously injected insulin is unpredictable in newborns with little subcutaneous fat, especially when the condition is associated with IUGR ${ }^{12)}$.

Insulin pump therapy allows for minute changes of dosage with meals during the day. The insulin pump can deliver small doses of insulin, about 0.05 units at a time; whereas the smallest insulin dose that can be accurately administered without dilution using a syringe is 0.5 units. The efficacy of insulin pump therapy has been well established in adult practice ${ }^{13)}$. It is also considered a safe and well-accepted method for pediatric diabetes $^{14,15)}$. Some researchers have described the safety and efficacy of CSII in NDM ${ }^{4,5,16)}$. However, there is no consensus on the use of insulin pump for NDM, and it is not widely used in clinical practice for treatment of NDM.

In this case, we introduced insulin pump therapy for the treatment of a newborn with TNDM. The patient's glucose levels were soon stabilized without hypoglycemia. The excellent glycemic control obtained after CSII may not be solely due to the use of an insulin pump. It is also possible that the infant, whose condition appeared to be transient NDM, was already in the recovery phase of beta cell function.

We conclude that insulin pump therapy is a safe and effective mode of treatment for NDM. Early adoption of insulin pump therapy for NDM may also shorten the length of hospital stays.

\section{Conflict of interest}

No potential conflict of interest relevant to this article was reported.

\section{References}

1. von Muhlendahl KE, Herkenhoff H. Long-term course of neonatal diabetes. N Engl J Med 1995;333:704-8.

2. Polak M, Cave H. Neonatal diabetes mellitus: a disease linked to multiple mechanisms. Orphanet J Rare Dis 2007;2:12.

3. Burns CM, Rutherford MA, Boardman JP, Cowan FM. Patterns of cerebral injury and neurodevelopmental outcomes after symptomatic neonatal hypoglycemia. Pediatrics 2008;122:65-74.

4. Bharucha T, Brown J, McDonnell C, Gebert R, McDougall P, Cameron F, et al. Neonatal diabetes mellitus: Insulin pump as an alternative management strategy. J Paediatr Child Health 2005;41:522-6.

5. Wintergerst KA, Hargadon S, Hsiang HY. Continuous subcutaneous insulin infusion in neonatal diabetes mellitus. Pediatr Diabetes 2004;5:202-6.

6. Temple IK, Mackay DJ, Docherty LE. Diabetes mellitus, 6q24-related transient neonatal. In: Pagon RA, Adam MP, Bird TD, Dolan CR, Fong CT, Stephens K, editors. GeneReviews" [monograph on the Internet]. Seattle (WA): University of Washington, Seattle, 2005 Oct [updated 2012 Sep 27; cited 2013 Sep 10]. Available from;http://www.ncbi. nlm.nih.gov/pubmed/20301706.

7. Gloyn AL, Pearson ER, Antcliff JF, Proks P, Bruining GJ, Slingerland AS, et al. Activating mutations in the gene encoding the ATP-sensitive potassium-channel subunit Kir6.2 and permanent neonatal diabetes. N Engl J Med 2004;350:1838-49.

8. Vaxillaire M, Populaire C, Busiah K, Cave H, Gloyn AL, Hattersley AT, et al. Kir6.2 mutations are a common cause of permanent neonatal diabetes in a large cohort of French patients. Diabetes 2004;53:2719-22.

9. Babenko AP, Polak M, Cave H, Busiah K, Czernichow P, Scharfmann R, et al. Activating mutations in the 
ABCC8 gene in neonatal diabetes mellitus. N Engl J Med 2006;355:456-66.

10. Temple IK, Shield JP. Transient neonatal diabetes, a disorder of imprinting. J Med Genet 2002;39:872-5.

11. Docherty LE, Poole RL, Mattocks CJ, Lehmann A, Temple IK, Mackay DJ. Further refinement of the critical minimal genetic region for the imprinting disorder 6q24 transient neonatal diabetes. Diabetologia 2010;53:2347-51.

12. Sindelka G, Heinemann L, Berger M, Frenck W, Chantelau E. Effect of insulin concentration, subcutaneous fat thickness and skin temperature on subcutaneous insulin absorption in healthy subjects. Diabetologia 1994;37:377-80.

13. Mecklenburg RS, Benson EA, Benson JW Jr, Blumenstein
BA, Fredlund PN, Guinn TS, et al. Long-term metabolic control with insulin pump therapy: report of experience with 127 patients. N Engl J Med 1985;313:465-8.

14. Shalitin S, Phillip M. The use of insulin pump therapy in the pediatric age group. Horm Res 2008;70:14-21.

15. Weinzimer SA, Swan KL, Sikes KA, Ahern JH. Emerging evidence for the use of insulin pump therapy in infants, toddlers, and preschool-aged children with type 1 diabetes. Pediatr Diabetes 2006;7 Suppl 4:15-9.

16. Tubiana-Rufi N. Insulin pump therapy in neonatal diabetes. Endocr Dev 2007;12:67-74. 